\title{
In vitro growth of some fastidious adenoviruses from stool specimens
}

\author{
AH KIDD* AND CR MADELEY $\dagger$ \\ From the University Department of Infectious Diseases and Regional Virus Laboratory, Ruchill Hospital, \\ Glasgow G20 9NB, UK
}

SUMMARY Sixty-seven stool specimens from 51 children, positive for adenoviruses by electron microscopy and negative for growth in human-embryo kidney cells, were tested for growth in Chang conjunctiva cells. Twenty-eight specimens caused a cytopathic effect over more than one passage in these cultures, and several adenovirus strains grew better at $33^{\circ} \mathrm{C}$ than at $37^{\circ} \mathrm{C}$. Most of the culturepositive specimens also induced the development of adenovirus antigens in $\mathrm{KB}$ cells detectable by a group-specific indirect immunofluorescence test. Twenty-four of the 25 fastidious strains tested were antigenically related and were distinct from the established serotypes commonly isolated from stools.

Adenoviruses that cannot be isolated in the cultures used routinely to detect viruses have been recognised in the stool specimens of children by electron microscopy. ${ }^{1-5}$ Primary cultures of human-embryo kidney (HEK) cells may show a transient cytopathic effect, which cannot be passaged, ${ }^{34}$ and detection of intracellular adenovirus antigens by immunofluorescence has been reported. ${ }^{4-6}$ These strains have been called non-cultivable ${ }^{6}$ or enteric ${ }^{7}$ adenoviruses. We report some success in growing such strains and present some evidence that they may belong to a new serotype. Since growth of some of them is demonstrated it will be more correct to refer to these adenoviruses as fastidious $(F)$ strains.

\section{Material and methods}

Stool extracts were made in phosphate buffered saline from 67 specimens obtained from 51 children. All were positive for adenoviruses by electron microscopy and negative by culture in HEK cells. The methods for preparing and examining specimens of stool for electron microscopy have already been published. ${ }^{3}$

Chang conjunctiva D cells ${ }^{8}$ (ATCC No. CCL 20.2, supplied by Flow Laboratories Ltd, Irvine,

\footnotetext{
*Present address: Department of Virology, St Thomas' Hospital and Medical School, London SE1 7EH.

tPresent address: Department of Virology, University of Newcastle upon Tyne, Royal Victoria Infirmary, Newcastle upon Tyne NE1 4LP.

Accepted for publication 9 July 1980
}

Scotland) were grown as test-tube cultures in medium 199 with Hanks' basal salt solution, $10 \%$ fetal calf serum, and antibiotics. Cultures were infected with $0.1 \mathrm{ml}$ stool extract clarified by low-speed centrifugation. The cultures were incubated stationary at $33^{\circ} \mathrm{C}$ or $37^{\circ} \mathrm{C}$ in Leibovitz' L15 medium ${ }^{10}$ containing penicillin, streptomycin, and $2 \%$ uninactivated fetal calf serum. As necessary, the cultures were frozen and thawed four times before $0.1 \mathrm{ml}$ was used to inoculate fresh cultures. In some experiments 5-bromo-2'-deoxyuridine, which interferes with normal DNA replication, was incorporated in the maintenance medium at $50 \mu \mathrm{g} / \mathrm{ml}$.

Antisera to $F$ adenovirus were prepared by inoculating two rabbits with a crude clarified stool extract passed through a $0.22 \mu \mathrm{m}$ membrane filter and checked for bacterial sterility before use. The stool specimen was obtained from a child who shed adenoviruses (which could not be grown in HEK cells) in five stools taken over eight days. Three weekly injections of $1.25 \mathrm{ml}$ were given intravenously, and the animals were bled one week later.

Group-specific anti-adenovirus sera were prepared by a method used by Dr CM Patricia Bradstreet, Public Health Laboratory Service Standards Laboratory, London (personal communication). Five guinea-pigs were inoculated by intranasal instillation of $0.2 \mathrm{ml}$ clarified cell culture fluid containing adenovirus type 3 . The animals were bled by cardiac puncture before immunisation and again 15 days after inoculation. Two of the sera were shown to contain good titres of group-specific 213 
antibody by preliminary tests, and one of these was used in the indirect immunofluorescence test.

$\mathrm{KB}$ cells for immunofluorescence were grown on coverslips in Leighton tubes. After inoculation with $0.1 \mathrm{ml}$ stool extract or $0.5 \mathrm{ml}$ prototype adenovirus strains, they were incubated at $37^{\circ} \mathrm{C}$ for three days before fixation in acetone. Rabbit (anti-F adenovirus) antisera at various dilutions, or guinea-pig (groupspecific) antisera at a dilution of $1: 20$, were added and, after washing, the preparations were treated with FITC-conjugated anti-species IgG (Nordic Immunological Laboratories, Maidenhead, Berks) at a dilution of $1: 10$. The coverslips were then washed, mounted in PBS-glycerol, and examined in a Leitz incident light-fluorescence microscope at a magnification of $\times 250$. Appropriate control preparations were also examined.

Fetal human intestinal segments were obtained from surgical terminations at eight to 12 weeks' gestation. Organ cultures were prepared from these segments by the method of Dolin et al. ${ }^{11}$ They were infected by the addition of $0.1 \mathrm{ml}$ clarified stool extract and were incubated at $37^{\circ} \mathrm{C}$ in Leibovitz' L15 medium containing $0.2 \%$ bovine albumin and antibiotics. The culture fluids were replaced every second day. The harvested fluids were examined for the presence of adenovirus by electron microscopy and were used to inoculate HEK and Chang cell cultures.

\section{Results}

Chang conjunctiva cell cultures were inoculated with the 67 specimens and incubated at $33^{\circ} \mathrm{C}$. Whereas none of the specimens caused a marked cytopathic effect in HEK cells, $28(42 \%)$ from 24 children caused a cytopathic effect characteristic of adenovirus over more than one passage in Chang cells. Eleven of the 28 caused a cytopathic effect beyond the third passage, and the first two specimens to be studied have caused cytopathic effects over eight passages so far. This represents a $10^{-8}$ dilution of the original stool extract. Since a $10^{-2}$ dilution of the second-passage fluids was no longer capable of initiating a cytopathic effect, carry-over of a toxic factor from the stool to later passages is unlikely. Further, the addition of the DNA-inhibitor 5bromo-2'-deoxyuridine to the culture medium inhibited the cytopathic effect of all 14 specimens against which it was tested. Therefore it is likely that development of the cytopathic effect depends on the synthesis of functional DNA, and this is additional evidence that the cytopathic effect was not just a toxic effect.

Cytopathic effect developed in Chang cells over more passages at $33^{\circ} \mathrm{C}$ than at $37^{\circ} \mathrm{C}$ (Table), although the time in culture was approximately the same at each temperature. Sixteen specimens containing $F$ adenoviruses were incubated in Chang cell cultures at both temperatures in parallel, and 11 caused a cytopathic effect. Ten of these caused a cytopathic effect over at least one more passage at $33^{\circ} \mathrm{C}$ than at $37^{\circ} \mathrm{C}$.

$\mathrm{KB}$ cells were also inoculated with the original stool extracts and tested for the presence of adenovirus antigens by immunofluorescence three days

Results of cell culture and immunofluorescence tests with 16 stool specimens known to contain adenoviruses by EM

\begin{tabular}{|c|c|c|c|c|c|c|c|c|c|c|c|c|c|c|}
\hline \multirow[t]{4}{*}{ Patient } & \multirow[t]{4}{*}{ Date of specimen } & \multicolumn{10}{|c|}{ Cytopathic effect } & \multirow{4}{*}{$\begin{array}{l}\text { Inhibition } \\
\text { by } 5-B U d R\end{array}$} & \multirow{3}{*}{\multicolumn{2}{|c|}{$\begin{array}{l}\text { Immuno- } \\
\text { fluorescence } \\
\text { in } \mathrm{KB} \text { cells } \\
\text { inoculum }\end{array}$}} \\
\hline & & \multicolumn{3}{|c|}{$H E K 37^{\circ} \mathrm{C}$} & \multicolumn{3}{|c|}{ Chang $37^{\circ} \mathrm{C}$} & \multicolumn{4}{|c|}{ Chang $33^{\circ} \mathrm{C}$} & & & \\
\hline & & \multirow{2}{*}{$P 1$} & \multirow{2}{*}{$P 2$} & \multirow{2}{*}{$P 3$} & \multirow{2}{*}{$P 1$} & \multirow{2}{*}{$P 2$} & \multirow{2}{*}{$P 3$} & \multirow{2}{*}{$P I$} & \multirow{2}{*}{$P 2$} & \multirow{2}{*}{$P 3$} & \multirow{2}{*}{$P 4$} & & & \\
\hline & & & & & & & & & & & & & $S E^{*}$ & $P 2 \dagger$ \\
\hline $\mathbf{A}$ & 14 May '78 & - & - & - & - & - & - & - & - & - & NT & NA & - & NT \\
\hline B & 1 Aug '78 & - & - & - & - & - & - & - & - & - & NT & NA & - & NT \\
\hline D & 21 Aug '78 & + & - & - & + & + & - & + & + & + & - & + & + & - \\
\hline E & 29 Aug '78 & - & - & - & $?$ & - & - & + & + & + & + & + & + & + \\
\hline $\mathbf{F}$ & 30 Aug '78 & $?$ & - & - & + & $?$ & - & + & + & + & - & + & NT & NT \\
\hline$F$ & 31 Aug '78 & + & - & - & + & $?$ & - & + & + & + & - & + & + & + \\
\hline G & 18 Sept '78 & - & - & - & - & - & - & - & - & - & NT & NA & - & NT \\
\hline $\mathbf{H}$ & 3 Oct '78 & - & - & - & + & - & - & + & + & $?$ & - & + & + & + \\
\hline I & 21 Oct '78 & + & - & - & + & $?$ & - & + & + & + & - & + & + & - \\
\hline $\mathbf{J}$ & 7 Feb '79 & - & - & - & + & - & - & + & + & + & - & + & + & + \\
\hline $\mathbf{J}$ & 12 Feb '79 & - & - & - & - & - & - & - & - & - & NT & NA & - & NT \\
\hline $\mathbf{K}$ & 5 Mar'79 & - & - & - & $?$ & - & - & + & $?$ & - & NT & + & + & - \\
\hline L & 6 Mar'79 & + & - & - & + & + & - & + & + & + & + & + & + & + \\
\hline $\mathbf{L}$ & 9 Mar '79 & - & - & - & $?$ & - & - & + & + & + & + & + & - & NT \\
\hline
\end{tabular}

*Indirect immunofluorescence test using KB cells inoculated with stool extract and fixed three days postinoculation.

$\dagger$ Indirect immunofluorescence test as above but using KB cells inoculated with second passage Chang conjunctiva ' $D$ ' cell culture fluids from cultures incubated at $33^{\circ} \mathrm{C}$.

NT $=$ not tested; NA $=$ not applicable.

$?=$ Transient cytopathic effect which did not persist nor develop. 
after inoculation with group-specific guinea-pig antiserum. The specimens that gave positive results by immunofluorescence also caused a cytopathic effect in Chang cells. With one exception (patient $\mathrm{L}$ on 9 March 1979), the specimens that were negative by immunofluorescence did not cause a cytopathic effect. The fluorescence observed was confined to single cells, which accords with the results of other workers. ${ }^{5}$

All the fastidious strains detected in Chang cell cultures have given the same kind of cytopathic effect which, though adenovirus-like, is recognisably different from that produced by the established serotypes commonly isolated from stools and by wild strains of types 12,18 , and 31 . Three strains that were particularly cytopathogenic were not neutralised by standard typing antisera to adenovirus types 1 to 33 .

The rabbit antisera prepared against $F$ adenoviruses from one child had no neutralising activity against adenovirus types $1,2,3,5$, and 7 , which are those isolated most frequently from stools. The sera, however, had significant titres (equal to or greater than a fourfold increase in titre over the pre-immune serum) to adenovirus antigens in $\mathrm{KB}$ cells infected with type 2 or type 3 using the indirect immunofluorescence test. Similar seroconversion was detected by complement fixation, and both results indicate that the rabbits had developed groupspecific antibodies to adenoviruses of mammalian origin.

The postinoculation sera diluted 1:20 prevented the development of a cytopathic effect caused by 24 of the 25 specimens containing $F$ adenoviruses that were tested. One of the sera had a titre of at least 1:640 against nine of the nine strains tested. The sera could not, however, be tested against the homologous virus since none of the specimens from this child caused sufficient cytopathic effect to be used in a neutralisation test. $\mathrm{F}$ adenoviruses (showing different degrees of infectivity in Chang cells) from this child and five others have been found to be related antigenically and distinct from the 35 established serotypes by ELISA. ${ }^{12}$ The preliminary neutralisation and ELISA results together suggest that $\mathrm{F}$ adenoviruses are a new serotype.

Sets of six replicate organ cultures were inoculated with three stools, each from a different child. Adenoviruses were seen by electron microscopy in some culture fluids after 14 days (after six complete changes of medium) but fluids taken on day 16 did not cause a cytopathic effect in HEK cells. The same fluids were then used to inoculate Chang cells. All six fluids from two of the three sets of replicate organ cultures taken on day 16 caused a cytopathic effect in Chang cells. Fluids from control (uninoculated) organ cultures did not cause a cytopathic effect. In all cases where a cytopathic effect was seen, it was neutralised by the anti-F adenovirus rabbit serum diluted 1:20.

\section{Discussion}

Diarrhoea in infancy is a major health problem and has been given priority by the World Health Organization. How much is due to viruses is still the subject of research, but progress has been handicapped by failure to grow the viruses detected in faeces by electron microscopy and other methods.

Our results show that the use of Chang conjunctiva cells may help to solve this problem, at least with adenoviruses. The success in detecting some $42 \%$, however, still leaves the non-growth of the other $58 \%$ to be explained. Other (unpublished) results do not suggest that this failure to grow is due to antibody on the virus or to inhibitors in the stool extract. Why some stool adenoviruses from a child grow and others do not, even when the specimens are taken on the same day (patient $J$ on 12 February 1979, see Table), also requires explanation.

$F$ adenoviruses have been implicated in outbreaks of diarrhoea and vomiting in children. ${ }^{14}$ It is possible that they are infectious to cell cultures only at a particular stage of infection in an individual, and this stage may or may not be associated with illness. Even with cytopathogenic strains, however, infectivity in Chang cell cultures is low. Whereas wild strains of common established serotypes adapt more and more to cell culture on passage, most $F$ strains do not. The inhibition by bromo-deoxyuridine suggests that virus replication occurred, but this was limited in some way, perhaps by the absence of some necessary condition or factor present in vivo. The closest parallel to in vivo conditions that can be achieved in vitro is probably organ culture using fetal human intestine. The absence of normal gut contents and possible alterations to the normal mucosa while in culture means that even this system is different from conditions in vivo. In addition, supplies of fetal gut are irregular and likely to decrease. Our limited results with this technique suggest that it should be evaluated further for the recovery of new infectious virus after inoculation with F strains.

The significance of detecting a cytopathic effect over a greater number of passages in Chang cells at $33^{\circ} \mathrm{C}$ than at $37^{\circ} \mathrm{C}$ is not known. The large numbers of adenovirus particles that must be present in a stool before they can be seen by the insensitive technique of electron microscopy indicates that considerable replication occurs somewhere in the body. The most likely site is the gut, but $\mathrm{F}$ adeno- 
viruses may still preferentially infect cooler sites such as the respiratory tract and/or the conjunctivae, with opportunist invasion of the gut cells. This could mean that transmission to other susceptibles can occur from the respiratory tract as well as from the lower gut.

Our preliminary serological results have shown that the cytopathogenic strains among these stool adenoviruses were not common established serotypes. Several strains of $F$ adenovirus and the neutralising antisera have been sent to an adenovirus reference laboratory for confirmation since it was impractical to attempt culture of all 35 previously described serotypes to set up our own confirmatory tests. It is relevant that Gary et al. ${ }^{6}$ prepared antisera to three strains of adenovirus that could not be cultured, and these had little or no neutralising activity against the 35 established serotypes. Moreover, six strains of $F$ adenovirus from our laboratory were antigenically distinct from the 35 established serotypes by ELISA, irrespective of infectivity in Chang cell cultures. ${ }^{12}$ Since both preliminary neutralisation tests and ELISA suggest that most $F$ adenovirus strains are related, the reasons for differences in infectivity with different strains may be other than the antigenic composition of the virus.

The $\mathrm{F}$ adenoviruses appear to be common, and, if confirmed as a new serotype (or a new subgroup), they may be more common than the established serotypes that are frequently isolated. The use of Chang conjunctiva cells should allow not only the detection of some adenovirus strains previously thought to be non-cultivable, but also further characterisation of these viruses.

This work was aided by a grant from the Scottish Hospitals Endowment Research Trust (HERT 484), whose support is gratefully acknowledged. AHK held the Sir Maurice Bloch Fellowship of the University of Glasgow.

References

1 Flewett TH, Bryden AS, Davies H, Morris CA. Epidemic viral enteritis in a long-stay children's ward. Lancet $1975 ; \mathbf{i}: 4-5$.

2 White GBB, Stancliffe D. Viruses and gastroenteritis. Lancet $1975 ; \mathbf{i i}: 703$.

${ }^{3}$ Madeley CR, Cosgrove BP, Bell EJ, Fallon RJ. Stool viruses in babies in Glasgow. 1. Hospital admissions with diarrhoea. J Hyg Camb 1977;78:261-73.

* Richmond SJ, Caul EO, Dunn SM, Ashley CR, Clarke SKR, Seymour NR. An outbreak of gastroenteritis in young children caused by adenoviruses. Lancet 1979;i: 1178-80.

${ }^{5}$ Retter M, Middleton PJ, Tam JS, Petric M. Enteric adenoviruses: detection, replication and significance. $J$ Clin Microbiol 1979;10:574-8.

${ }^{6}$ Gary GW, Hierholzer JC, Black RE. Characteristics of noncultivable adenoviruses associated with diarrhoea in infants: a new subgroup of human adenoviruses. J Clin Microbiol 1979;10:96-103.

' Jacobsson PA, Johansson ME, Wadell G. Identification of an enteric adenovirus by immunoelectroosmophoresis (IEOP) technique. J Med Virol 1979;3:307-12.

s Chang RS. Continuous sub-cultivation of epithelial-like cells from normal human tissues. Proc Soc, Exp Biol $\vec{C}$ Med 1954;87:440-3.

${ }^{9}$ Wong SC, Kilbourne ED. Changing viral susceptibility : of a human cell line in continuous cultivation. $J$ Exp Med 1961;113:95-110.

10 Leibovitz A. The growth and maintenance of tissue-cell cultures in free gas exchange with the atmosphere. Am J Hyg 1963;78:173-80.

11 Dolin R, Blacklow NR, Malmgren RA, Chanock RM Establishment of human fetal intestinal organ cultures for growth of viruses. $J$ Infect Dis 1970;122:227-31.

12 Johansson ME, Uhnoo I, Kidd AH, Madeley CR, Wadell $G$. Direct identification of enteric adenovirus, a candidate new serotype associated with infantile gastroenteritis. J Clin Microbiol 1980;12:95-100.

Requests for reprints to: Professor CR Madeley, Department of Virology, Royal Victoria Infirmary, Newcastle upon Tyne NE1 4LP. 